\title{
Some features of Boiler Design and Construction in Relation TO UPKEEP.
}

Paper read before the Institution by $A . E$. KYFFIN, Member, Manchester, on $3^{\text {rd }}$ November, 1922, in Manchester.

\section{PAPER No. 131.}

In this Paper it is not intended to consider the boiler in its functions as a steam producer, the object being to bring before the members of this Institution some of the more important details of locomotive type boilers in which considerable diversity of practice exists, and which, while they are but parts of the boiler, yet have an important bearing on the life and maintenance of it as a whole, more especially when considered from the running shed and repair shop point of view. Reference to foreign practice has been almost entirely avoided as tending to complicate the questions dealt with.

\section{Tube Arrangement, etc.}

Apart from the water-space stays there is no part of a boiler which causes more anxiety and trouble than the firebox tubeplate, and the extent and frequency of the trouble depends to a large extent on the arrangement of the tubes. in this plate. 
Broadly, there are two systems of arranging tubes, namely, vertical and horizontal rows, as shown in Figs. I and 2.

The claim generally made for the first system is, that by reason of the tubes being directly under one another there is less opportunity for scale to collect, and also that

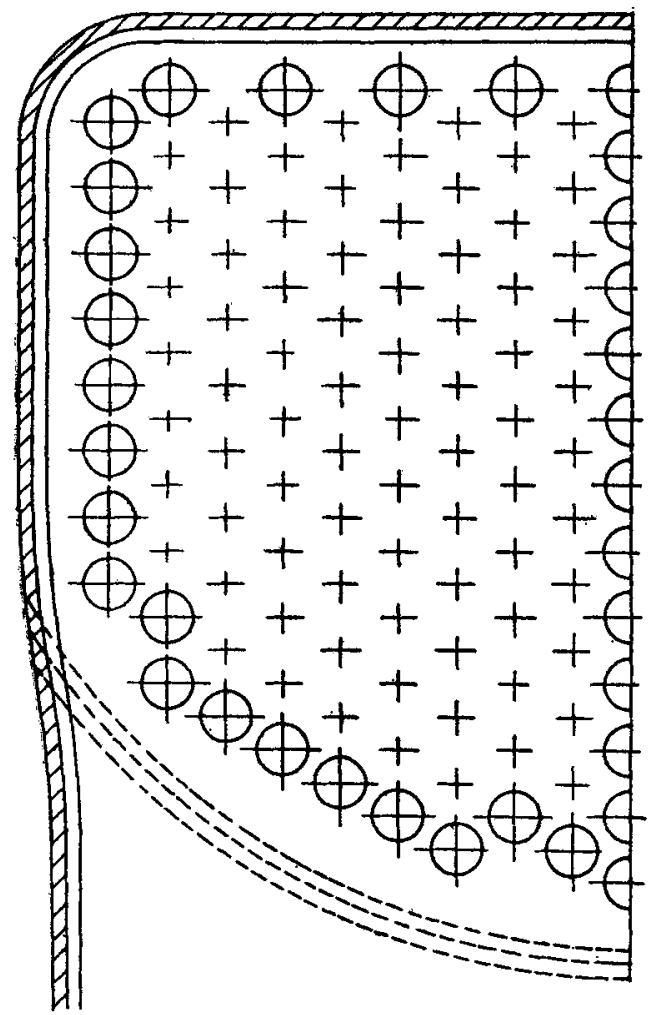

FIG. I.

the steam bubbles are not impeded in their upward course; but when the two outer rows are considered in their relation to the flange of the plates it would seem that the small section presented by the aggregate of the bridges of metal offers but small resistance to the flexure of the plate due to the expansion of the tubes, and thus cracks are more readily developed than is the case with the far greater section offered at the outer rows with the horizontal rows 
of tubes. This is sometimes recognised and every other tube pitch left out in some designs.

Many examples exist in which designers have crowded far too many tubes into the boilers with a view to getting "paper" heating surface, with the result that the bridges in the tubeplate are often as small as sin.; this not only

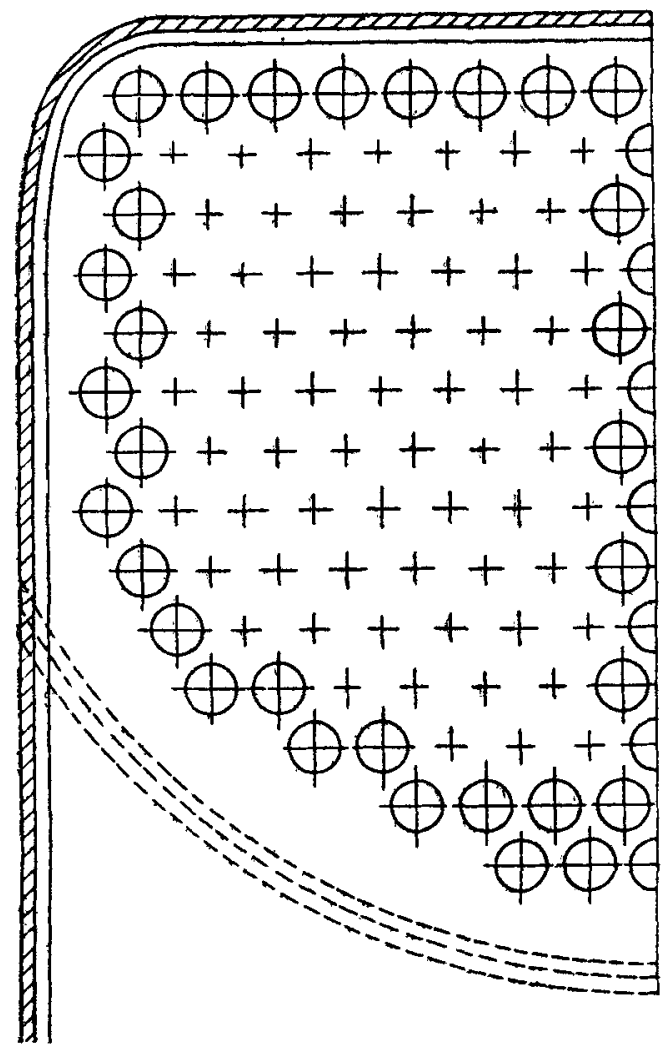

FIG. 2 .

leads to cracks at an early stage, but makes it next to impossible to remedy such cracks by the usual methods, as there is not sufficient metal to tap into. A further fault with such crowding is, that unless the water is very good the spaces between the tubes are rapidly made up, as it is next to impossible to wash out, however ample the provision made for so doing. 
Another fault often found, which also follows from the desire to get a lot of tubes in, is the placing of tubes right into the radius of the flange of the plates; this practice cannot be too severely condemned.

If tubes were spaced so as to give say, a minimum of $\frac{7}{8}$ in. bridge and were kept at least a tube diameter clear of the radius of the flange of the plates, there is little doubt but that the life of tubeplates would be prolonged and many anxious moments spared to those in charge of the engines; and it is extremely doubtful if, over a length of time, the boiler would prove any worse a steamer, for all railway men know that a large percentage of the tubes can be plugged before the steaming capacity drops.

Tubes are often placed too near the bottom of the barrel, with the result that washing out cannot be satisfactorily done and the circulation of the water along the bottom of the barrel into the front leg of the firebox is impeded; in most cases the bottom row and the outer tubes of the row above could be left out with advantage.

The last mentioned arrangement, which is by no means unknown, brings out in an acute degree the question of palm stays to the tubeplate, as the distance between the top row of water-space stays and the nearest tubes is considerable.

Although there are instances of boilers without palm stays, their place being taken by combining a small radius in the throat plate and the raising of the top row of waterspace stays to the utmost, yet in most cases they are used in some form, but their record of breakage is very high and many different forms have been evolved to mitigate the trouble, such as anchoring them several feet away from the tubeplate to give flexibility, and even of articulating them. In some designs the forged stay, into which the copper stay is screwed, stops short of the tubeplate by rin. or even more, whereas in other examples the forged stay is brought right up to the plate, each form having its advocate.

Another practice in palm stays is used on a few railways, namely, the provision of what are practically longitudinal stays between the tubeplates along the barrel bottom; this system, however, makes the washing out of the barreI more difficult and the stays are difficult to replace.

With the growth of boilers the practice of providing stays to the tubeplates in the tube area has increased to some extent, these being usually in the form of solid rods, although stay tubes, after marine practice, are sometimes found. The need for such stays is questionable in view of 
the enormous holding power of tubes, and it would be valuable information if evidence could be produced that tube leakage had been reduced or the life of the tubeplate prolonged by their use. The firm the Author is connected with has constructed boilers up to $6 \mathrm{ft}$. 6ins. diameter without any stays to the tube area, and no adverse reports have been received after many years.

\section{Water Space Stays.}

Many efforts have been made by designers to either eliminate or render these less liable to breakage, the best known of the devices for doing away with stays being the Jacob-Schupert firebox ; but as this form of construction does not lend itself to fireboxes carried between the frames it need not be considered in connection with British locomotives. Concerning the second class, in American practice, to some extent at least, flexible stays of the Tate type are fitted either to the whole firebox or more commonly to the breakage area. To the best of the Author's belief, these have not been tried in Great Britain, and it would be interesting to know why.

Locomotive engineers seem to have settled down to the practice, with copper fireboxes, of using plain copper stays, but there is by no means any standard as regards the diameter of such and areas supported by them. When boiler pressures were about I6o lbs., the usual rule was to use about rin. diameter stays supporting an area of about 16 sq. ins., but with the rise in pressures the area has naturally been reduced and in some cases $I \frac{1}{8}$ in. diameter stays used, either throughout the firebox or in the top rows ; but it is questionable whether the latter is advisable, as it means a very large stay has to be put in for renewals, and even a $1 \frac{1}{3}$ in. stay is a comparatively rigid bar which offers considerable resistance to the bending action imposed by the upward expansion of the firebox. It would be instructive if two boilers were made identical in all respects, saving that one should have, say, rin. stays spaced as widely as possible, and the other, say, $\frac{3}{4}$ in. stays spaced to suit the permissible tensile stress on the stays and a record kept over a period of the stay failures and the extent of the bulging of the plates.

It is highly desirable that water-space stays be made as long as possible, even if the firebox width, and therefore the number of tubes, suffer slightly ; also more consideration should be given than is often the case to the angle at which the stays enter the copper plate, as a bad angle of entry 
tends towards leaky stays; this feature is very noticeable in some, " waisted" fireboxes.

An interesting method of endeavouring to mitigate the breakage of stays in the area at the top front corners of the side plates is employed by two large railways the Author is acquainted with, namely, the provision of an additional stay in the centre of each ordinary spacing (see Fig. 8); but this arrangement would appear only to have the effect of rendering this area very rigid.

In the boilers of many locomotives built in this country for overseas lines the water-space stays have detector holes about $\frac{1}{8}$ in. diameter drilled in them, either for a distance of about $I_{4} \frac{1}{4}$. - that is, far enough to bring the hole into the water space-or else drilled right through and the outer end laid over or filled with a copper plug. Provided the water is reasonably good, these holes show the presence of fracturied stays, but with water which rapidly deposits scale the fracture, which ordinarily is of slow developmen $\bar{t}$, is filled up as it grows and the object of the hole is defeated.

As the subject of the methods of screwing in these stays has been dealt with in papers previously read before this Institution it is not proposed to refer to this matter; but quite a lot might be written regarding the form, diameter and thickness of the heads, but this point is left to the members to comment upon, mone especially regarding the burning off of these heads.

On the question of whether it is best to turn the threads off the portion of the stay between the inner and outer plate or to retain them opinions differ, as many engineers adopt the one form and many the other, but it seems reasonable to argue that the turned-down stay is the more flexible, and is also less liable to collect scale.

The pitch of stays in relation to the flanges of the tubes and door plates, foundation and firehole rings, requires attention, and many examples can be found in which the stays are brought unnecessarily close to such parts, thus preventing the firebox from breathing freely, and also providing areas in which scale can readily accumulate, but from which it is difficult to clean it.

\section{Firebox Crown Stays.}

Even at this late day locomotive engineers have not decided the question as to whether the Belpaire form is the best or not; thus while many large boilers of this type are built, there is also a large number of the round-topped 
variety; but if the latter gives perfect results, why do engineers continue to build the Belpaire box, which is undoubtedly heavier and more expensive? The answer to the question whether one type is better than the other can only be given by engineers who have both types under their supervision as regards running and repairs.

The roof bar or girder stay, while far from dead, is not so much used-for main line engines-as before; it is heavy, and it cannot be denied that it seriously hinders the cleaning

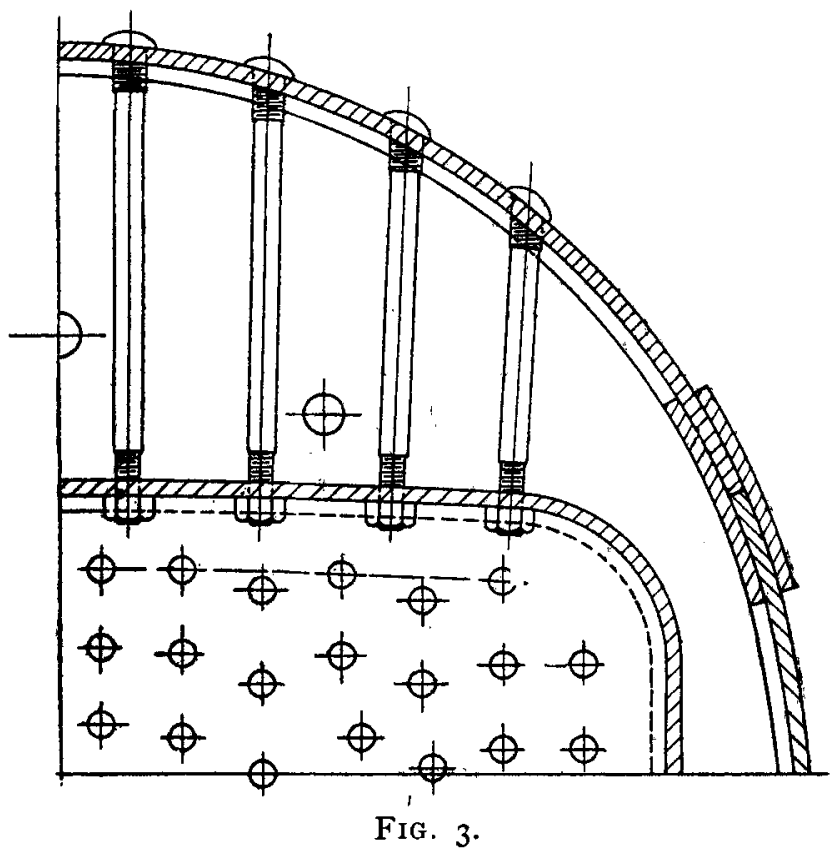

of the firebox top and is an admirable collector of scale. The alternative is, of course, the direct stay commonly in the form of a bolt screwed into the steel firebox shell top and the copper plate, being riveted over at the steel plate and nutted under the copper (see Fig. 3); but it is not unusual to have nuts both above and below the latter.

If plain direct stays are used, it is good practice to arch the crown of the copper box and arrange the stays radially so as to get as many full threads of the stays in both plates, but especially in the steel plate, as the stay end 
is riveted over at that end (see Fig. 4), which gives the cross section of two boxes-one with radial, the other vertical stays.

There are many other forms of roof stays devised to obviate the disadvantages of screwing the stays into the outer plate, some of which are shown in the accompanying sketches (Figs. 5 and 6). These all have their good features but all are more expensive than the plain stay.

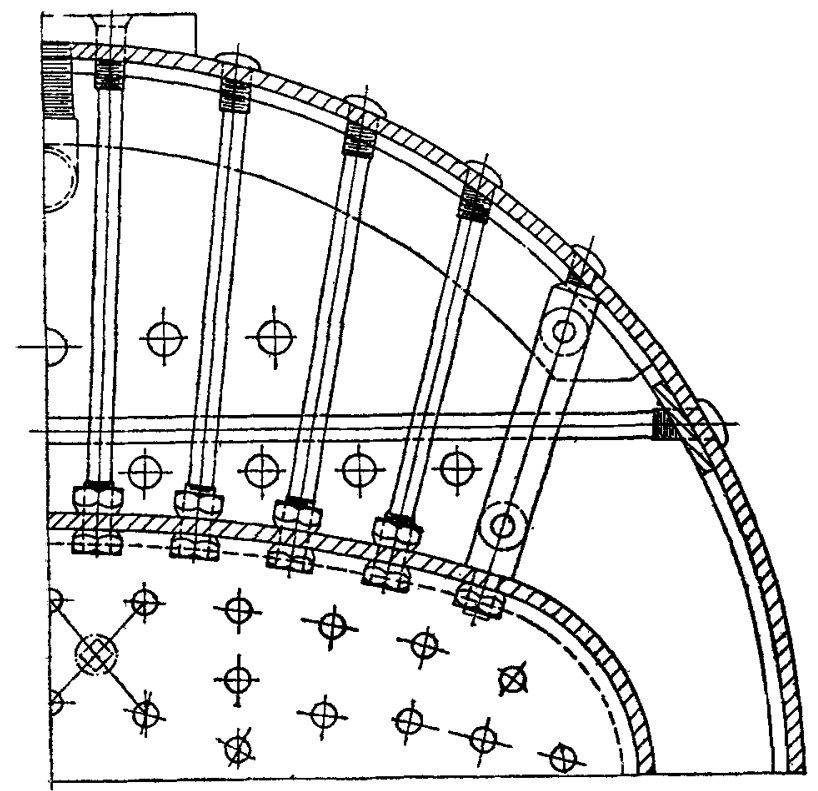

FIG. 4 .

It is usual to provide for the upward expansion of the tubeplate by arranging for the front two, three or even four rows of vertical stays to have a certain amount of free vertical movement, most commonly by attaching them in groups of twos or threes in a tee sling supported from the outer wrapper plates (see Figs. 7 and 8); there are, of course, other devices such as the provision of a few rows of stays of the types shown in Figs. 5 and 6. Cases are not uncommon in which such expansion stays are fitted above the back or door plates of fireboxes, but as this plate is rigidly attached to the shell plate by the firehole, the need for such flexible stays is questionable. One British railway, at least, 
builds all its boilers with the firebox crown stays slung in groups, as in Fig. 9.

\section{Firehole and Foundation Ring.}

The most common British type of firehole is a solid forged ring between the outer and inner firebox plate; this is often the full width of the water space, but sometimes the copper plate is dished to reduce the width of the ring to anything down to about $I \frac{3}{4}$ in., with the object of

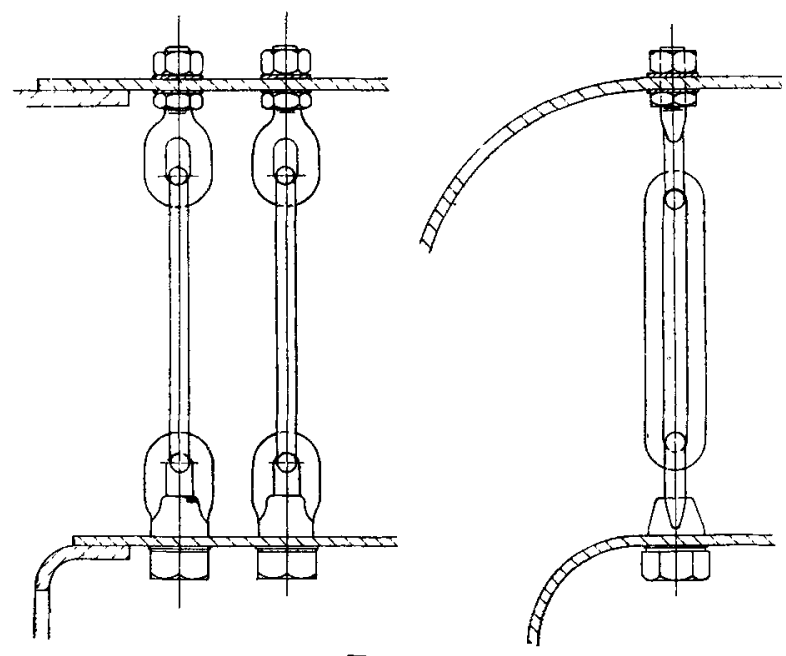

FIG. 5 .

shortening the rivets to ensure a tight joint and also of keeping the heads out of the flames; the objection to this practice is that with bad water the scale rapidly collects above the ring and is not easy to wash out. The rivets round a firehole are a constant source of trouble, and to avoid their use various methods are used of flanging both the copper and steel plate to form a joint without any ring. The best known form of this construction is the "Webb," used on the L. \& N.W. Railway, and to a limited extent elsewhere, and is too familiar to need any description. Some lines the Author is acquainted with, which at one time used this firehole, have now dropped it, as it was found that grooving rapidly developed in the steel plate at the top of the hole, owing to the breathing of the plate. Another method of construction is shown in Fig. IO; this differs from the 
"Webb" in that the steel plate is not dished round the hole but simply flanged, the rivets are more accessible, and the flanging blocks required are simpler than for the "Webb" type.

Foundation or bottom joint rings are almost invariably of rectangular section of an average width of $3^{\text {ins. to }} 4$ ins.

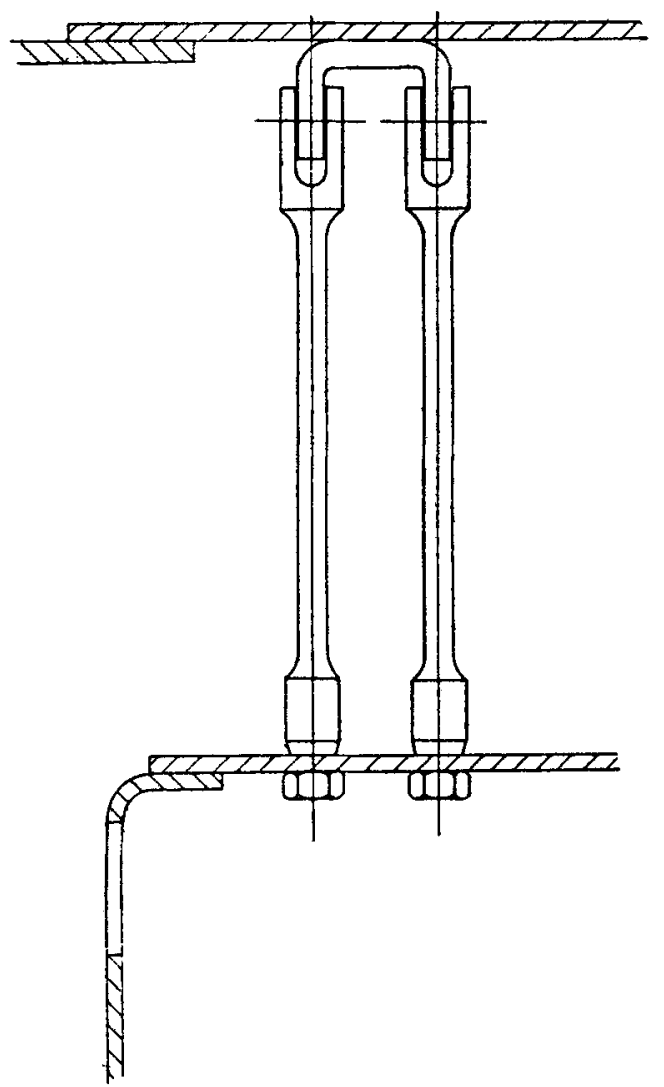

FIG. 6.

For boilers having a medium working pressure the riveting can be single, but above 160 lbs. double riveting is to be recommended. At the corners the rings are often made with a thinner downward extension to enable either a second or third row of rivets to be worked in according to whether the main portion of the rings is single or double riveted. 
This method of construction is very expensive, not only as regards the ring itself, but also in the machining of the boiler plates, and if a well-designed corner is used with the plain ring, equally good results can be obtained. The examination of the corners of many fireboxes occasions wonder as to how they keep tight at all, so badly are the rivets pitched, being either too large on the outside to be steamtight, or the inside copper plate is so cut away by the cluster of rivets that it cannot bed on to the ring. The

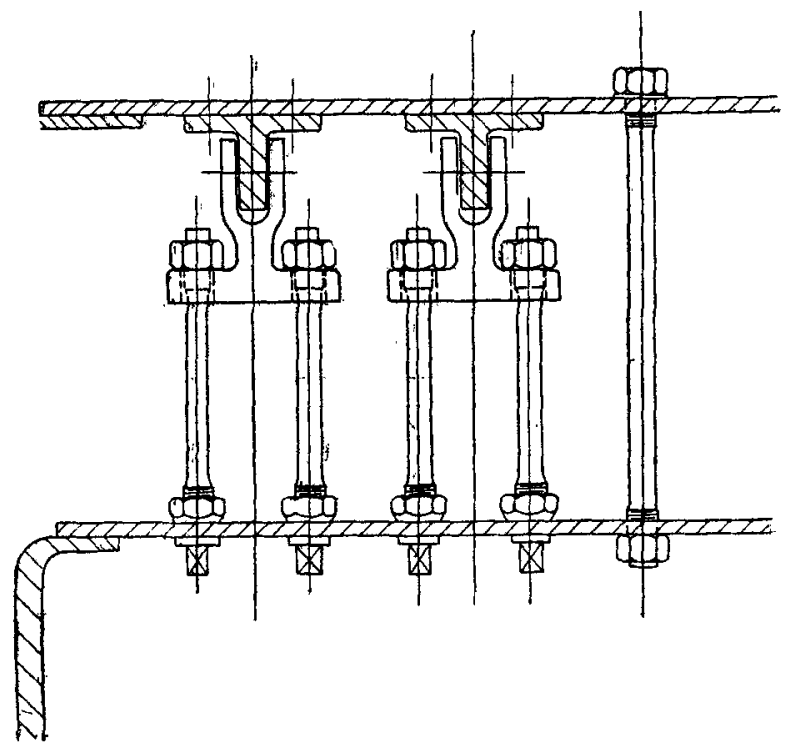

FIG. 7 .

use of screw rivets should be avoided as far as possible because if once they develop leaks they cannot be laid up again like an ordinary rivet, as this only tends to loosen the thread; and as the squares are always cut off they cannot be screwed up.

\section{Flanged Plates.}

The two principal plates are the throat or saddle and the back plate; the former is fairly immune from trouble with the exception of the flat between the shoulders at the top, where cracks sometimes develop, more especially if the joint is only the width necessary for single riveting. 
Regarding the back plate, an interesting difference of opinion exists as to the best radius for the flanging of the sides; the more usual figure is about $3 \frac{1}{2}$ ins. inside, but some engineers specify not less than 6ins. The Author has in his recollection a class of boiler which had the back plate flanged with a large radius, and in a comparatively short time it

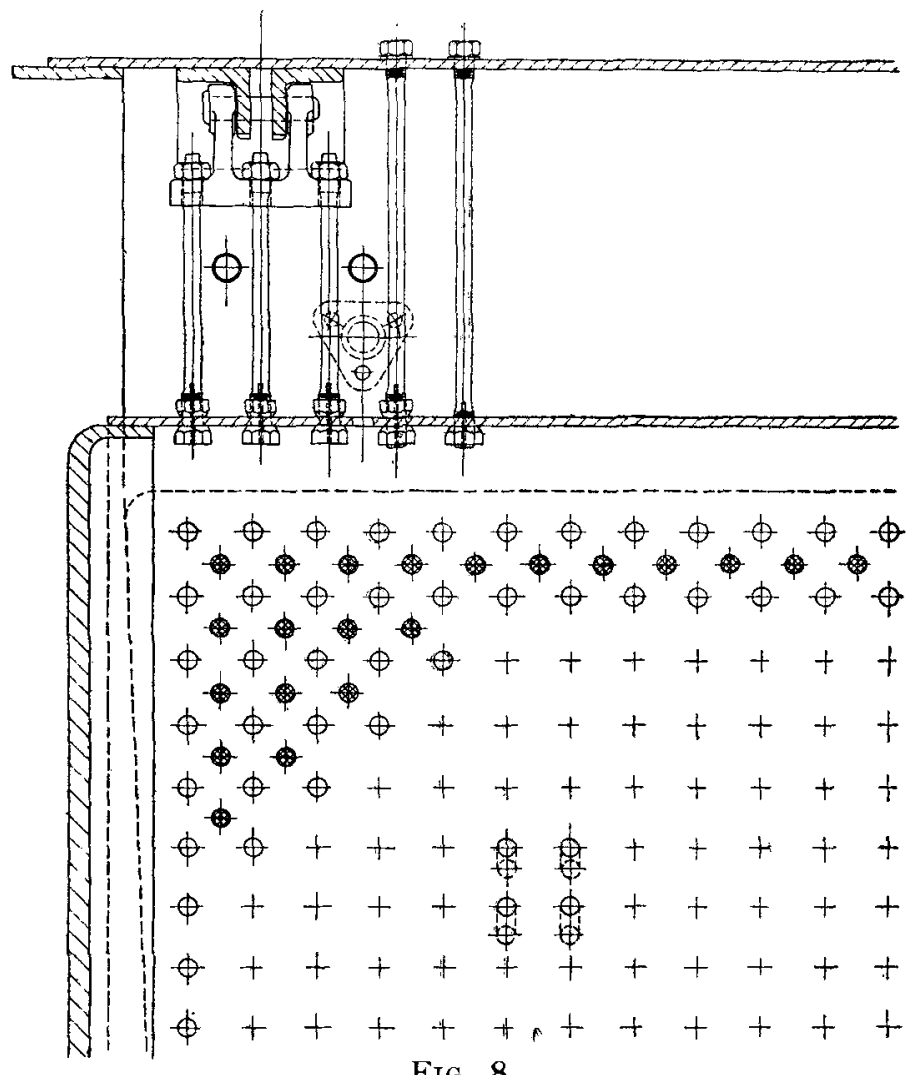

Fig. 8.

developed bad cracks at the junction of the radius and the flat of the plate at the upper portion of the firebox; this was attributed to the rigidness of the large tadius resisting the breathing of the back, and certainly the trouble disappeared when these plates were replaced with others of less radius. The form of back plates used on the L. \& N.W. Railway and some other lines, in which the flange is reversed in 


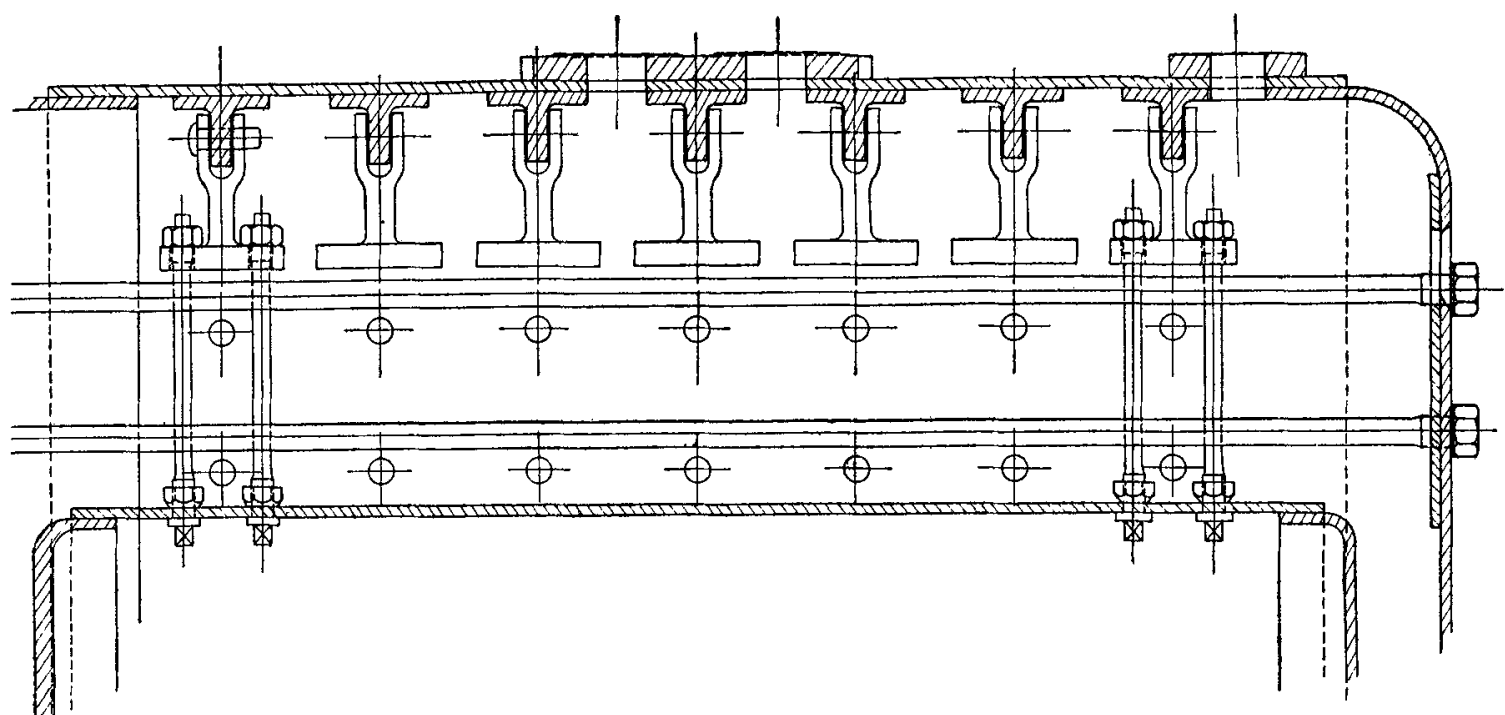

Fig. 9. 

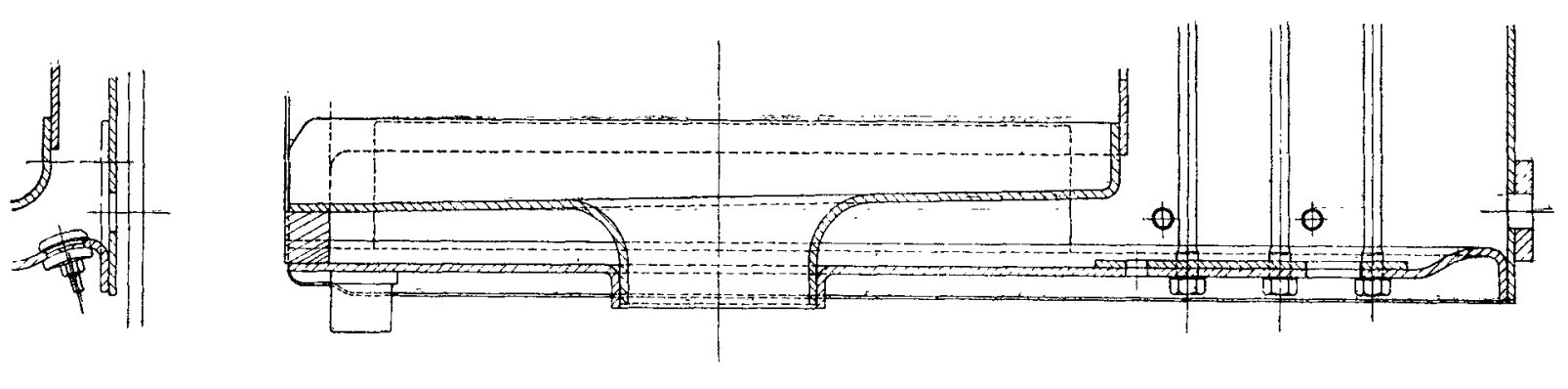

FIG. Iอ. 
direction from the conventional form (see Fig. Io), has certain claims made for it, but there are disadvantages also; a glance at the plan view of Fig. 1o will show the very considerable distance between the line of the riveted joint and the first row of water-space stays; this throws a very heavy stress on the latter and leaves a relatively large unstayed area of steel plate, and even when a few cross stays are put in, experience has shown that long vertical cracks occur. Similar trouble is experienced with the back plate, and generally it would be most instructive to hear from engineers who have to maintain and repair boilers of this type as to how, over a period of years, they compare with the ordinary type back plate.

\section{Tubes.}

The Author does not propose to enter upon the very debatable subject of the material of tubes, but much benefit is to be derived from a discussion regarding the methods of

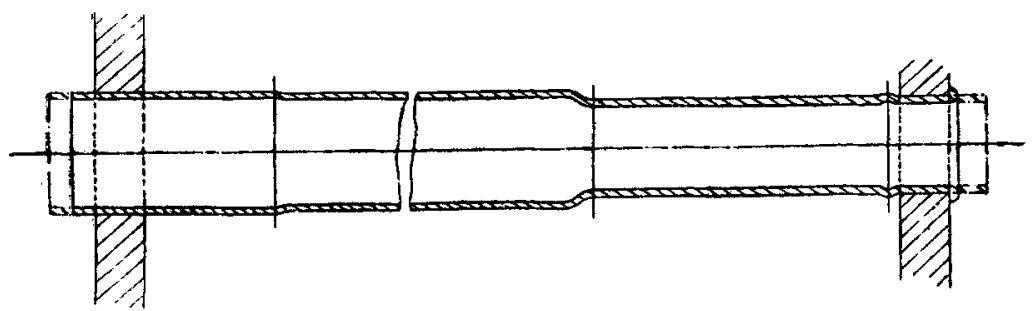

FIG. II.

securing tubes in the firebox tubeplate. The tubes may be simply rolled into place and slightly bell-mouthed, or they may be beaded right over; or again, they may have a shoulder roller on them next the water side of the tubeplate and beaded on the fire side, as in Fig. II. The use of ferrules is more common with copper and brass tubes than with steel, but there is not apparently any settled practice regarding whether ferrules should or should not be fitted into new boilers whatever be the material of the tubes.

\section{Wash-Out Arrangements.}

As relatively few railways have good water all over their systems, the provision of ample and convenient washout and inspection doors is of the utmost importance, as the cleanness of a boiler has much to do with its active life, not to speak of its steaming qualities. 
The average engineer in charge of the running of locomotives usually has to content himself with a few plugs, etc., in the region of the firebox foundation ring, a few in the smokebox tubeplate-often very inaccessible-two or three on the back of the firebox on the line of the firebox crown, and if the boiler has a Belpaire firebox, wash-outs on the firebox sides. These may, of course, be sufficient, but the provision of extra plugs or capped wash-outs on the radii of the front and back plate about half-way up, to enable the side water legs of the firebox to be washed out, would be a boon in most cases. Some railways fit a large mud door on the underside of the barrel a little ahead of the firebox so that any scale, etc., washed off the tubes and front

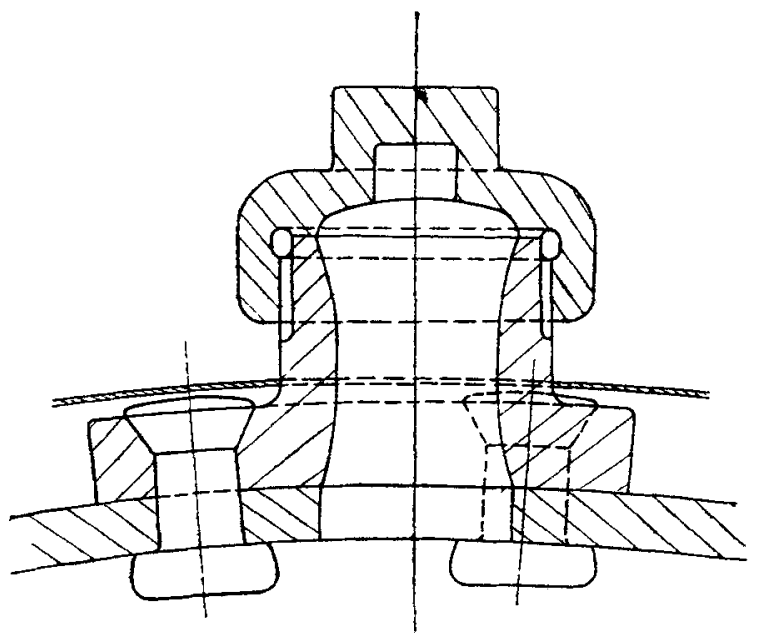

FIG. I 2 .

end of the barrel may be removed there instead of being washed into the front water-leg of the firebox. Provision is also made for washing the tubes and firebox top from above by fitting capped wash-outs on the front ring of the barrel and on the firebox crown next the barrel.

Regarding the actual details of wash-outs, these at the foundation ring are either taper plugs screwed direct into the steel plate-which is usually thickened by the provision of patch plates-or else into gun-metal seatings; or washouts with screwed capped tops are riveted or screwed on to the corners; the bodies of the latter may be of steel or gunmetal, with gun-metal caps on the lines of Fig. r2. The 
last mentioned practice is not so common on locomotives in use in Great Britain as on those for overseas. With a taper plug screwed direct into the plate it is only possible to get one plug at each corner of the firebox on the same level, but if seatings are used two plugs at right angles can be provided, while these can easily be arranged with capped wash-outs, provided, of course, there is room inside the frames.

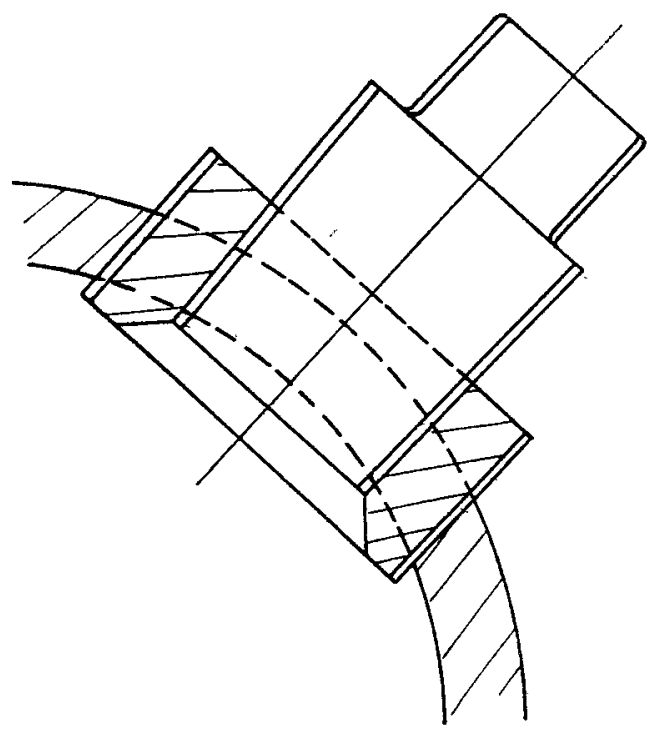

FIG. I 3.

The taper threads in the plates are soon damaged or worn and have frequently to be retapped, and in time become larger than the standard plugs. An interesting scheme for providing readily renewable holes is seen in Fig. I3, consisting of a steel ring screwed with a fine thread into the plate, the taper plug then being screwed into it, with the idea that the ring can be renewed when worn; but whether the remedy is worse than the evil is a debatable point.

The side wash-outs provided on fireboxes are usually taper plugs, capped wash-outs or removable handholes, one type of the latter being shown by Fig. I4; the handhole certainly provides the best access to the firebox top. These wash-outs are commonly located just above the line of the firebox crown, but are sometimes placed on the shoulders 


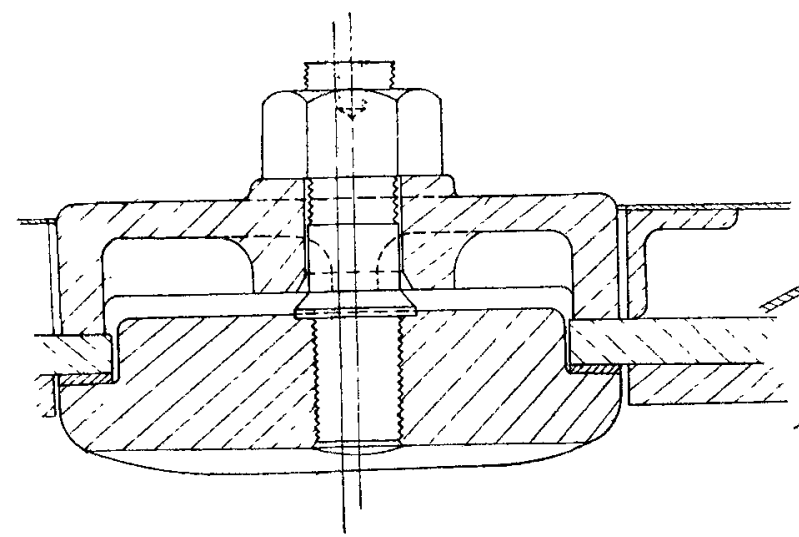

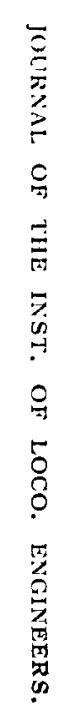


of the firebox to enable the stream of water to be directed downwards on to the firebox crown.

\section{Steam Domes.}

As these house the regulator and are the only means of getting to the main steam pipe, they are of great importance to the running shed force, yet on how many bollers are they of the type in which the joint line of the top is either above

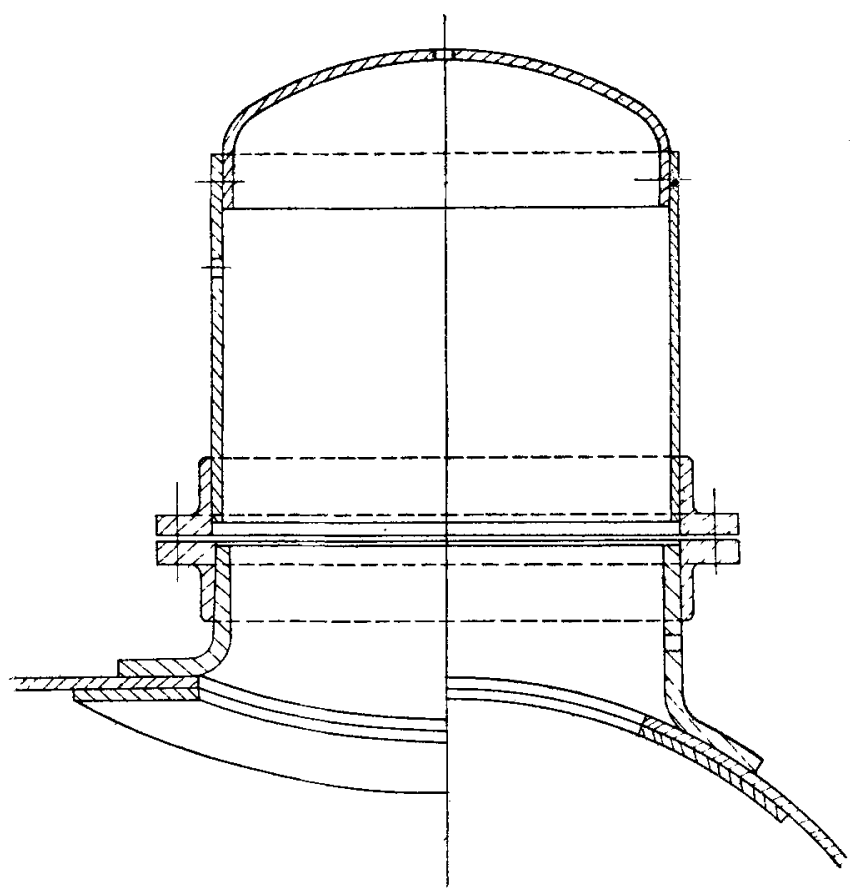

FIG. I 5.

the regulator head or only just level with it. The type of dome now most used on engines built in this country for overseas lines is shown in Fig. I 5 with this. When the upper portion is removed, the regulator head is so exposed that it can be easily refaced or otherwise attended to ; also the main steam pipe joint is fairly accessible, especially if the dome is, say, $2 \mathrm{ft}$. 3 ins. or $2 \mathrm{ft}$. 6ins. inside diameter.

$A$ leaking dome joint is always a nuisance and gives rise to considerable work; yet railway men do not seem to 
have decided whether the joint is best made by a copper ring of the continuous turned variety or the so-called boiled oil joint.

There are other important details of the boiler which, it may be claimed, have been ignored, but the Author's excuse must be that the Paper is not intended to be even moderately comprehensive, but he hopes that these somewhat disjointed notes will serve the purpose for which they are intended, namely, the gathering together of the experiences and opinions of the members of this Institution regarding the features in question.

\section{DISCUSSION.}

The Chairman : You have now heard Mr. Kyffin's Paper read, and are, I hope, anxious to proceed with its discussion. Before we do so I shall call on Mr. Jackson to propose a vote of thanks to the Author.

Mr. S. Jackson (Gorton Foundry): I have great pleasure in proposing that our thanks be given to $\mathrm{Mr}$. Kyffin for his very admirable Paper. The Author has exceptional opportunities for studying the subject, and he has certainly gone thoroughly into the question. Coming from what is called a "contract shop," Mr. Kyffin has availed himself of the opportunity of placing before us a variety of detail designs which can hardly be obtained elsewhere, and I am quite sure that his object to-night is to promote a discussion with a view to obtaining the criticisms of our "railway" members, who have experience in the upkeep of these boiler details.

To commence the discussion, I would call attention to Figs. I and 2. In Fig. I we have the tubes arranged in "vertical" rows and in Fig. 2 they are in "horizontal" rows.

Our own experience, gained from our clients' reports, shows that the life of the tubeplate is longer when the tubes are arranged as Fig. 2, than if pitched to Fig. I. Tubeplates to Fig. I crack along the vertical rows of tubes at each side near the flange, whereas plates to Fig. 2 do not appear to crack along the top row of tubes, nor do they crack at the sides.

Can any member explain why plates to Fig. I give way at the sides, and why plates to Fig. 2 do not give way at the top, the pitch of tubes and their relation to the respective flanges being the same in each case? 
Mr. J. N. Gresham (Messrs. Gresham \& Craven Ltd.) : I do not know that I can answer Mr. Jackson's question quite fully, but I can perhaps give one of the probable reasons. I think it is more than probable that the outside vertical row cracks first because it is subjected to the full range of temperature variation when the feed-water is put in, whereas the top horizontal row will only be subjected to a more or less even temperature while the engine is in service. In a number of tubeplate diagrams I have seen recently, it seems possible to trace a great deal of leaky tube trouble and cracked tubeplate trouble to the difference in temperature between the water in the boiler and the water fed in to the boiler. The latter being between zoodeg. and 25 odeg.F. colder naturally sinks to the bottom and so sets up strains. This cooling effect is, of course, most severe when the feed-water is put in while the engine is standing.

The Chairman: If I am not speaking out of my turn, I should like to mention an experience of cracked tubeplates which we had at one of our depots. In this case there was no question of large tubes or unduly narrow bridges, the cracks occurring between tube holes $\mathbf{I} \frac{3}{4}$ ins. diameter with bridges $\frac{7}{8}$ in. wide.

At this particular depot the water was very hard, containing both carbonates and sulphates of lime and magnesia in approximately equal quantities. The trouble practically disappeared when a water-softening plant was installed. This appears to prove that overheating of the tubeplate due to the impervious cement-like scale caused by deposition of the carbonates and sulphates together was the real cause of our troubles, as it doubtless is in many other cases, and that tube rigidity had little to do with it. In all such cases the first remedy I should suggest would be water softening.

Mr. W. E. Richards (Gorton Foundry) : One way which has been tried with a view to minimising the trouble from cracked tubeplates, though I cannot say with what results, has been to increase the pitch of the tubes in the neighbourhood of the top corners of the firebox. This secures wider bridges in the tubeplate, but entails the loss of a few tubes. and heating surface.

The Chairman: It may be of interest to know that we have had similar troubles with the upper portion of the firebox tubeplates with large superheater flue tubes occupying the whole width of the tubeplate. We overcame the trouble by replacing two large tubes in the two upper corners by two small tubes, and so reducing the superheater to one of .22 elements instead of 24 . 
We now always arrange to have at least one vertical row of small tubes between the tubeplate flange and the first vertical row of large tubes and have also eliminated all small tubes in the large tube area of the tubeplate.

These modifications have not only considerably reduced the liability to cracked bridges, but what is equally important, have greatly reduced the tendency to distortion of the tube holes after being at work for a time.

Mr. Jackson: Your point, Mr. Chairman, seems to be met by the fact that the large superheater tube in the corner of the tubeplate is stiffer, as a column, than small tubes. Small tubes may "sag" a little, thus allowing the corner of the tubeplate to give under expansion, whereas the large tube would hold the corner rigidly, and as the expansion of the copper box sides is in a forward direction, whilst that of the tubes is the contrary, it would appear that the corner of the tubeplate would crack through the large hole.

The Chairman: Do I understand that the suggestion is that the large tube has greater lateral rigidity, therefore exerts a greater axial force than a small tube when it alters its length by variation in temperature so that the tubeplate is more severely bent by these large tubes? The explanation appears plausible at first sight, but I am not prepared to accept it as complete.

The Author: Referring to the matter of large superheater flues and their influence on the copper tubeplate, I was recently shown by the engineer of a large Continental railway photographs and diagrams of the failure of tubeplates, and very remarkable these were; this gentleman informed me that in order to at least reduce the number of cracked plates, this railway has substituted medium-sized flues, about $2 \frac{1}{4}$ ins. diameter, and a period of years of service has shown decidedly beneficial results, which satisfied them, at least, that the cracks were due to use of large rigid flues.

The Chairman: I can endorse all the last speaker has said with regard to the advantages of the smaller flue tubes, though I cannot agree that their use is unknown in this country.

We have for some years had a considerable number of engines having flue tubes 3 ins. diameter, each containing a single loop of an element, two or three of the loops being connected in series. In some cases the whole of the tubes are 3 ins. diameter, and each contains a loop of an element. In others there are a few small tubes in the lower part of the tubeplate. 
In no instance have we had a cracked bridge or distorted tube hole in these tubeplates.

Mr. J. W. Glover: Mr. Kyffin has broadly given two systems of tube arrangements, viz., (I) with vertical rows, and (2) with horizontal, but there is a third arrangement which has been used with vertical rows of tubes and horizontal rows corresponding thereto-an arrangement frequently used in marine boiler practice.

We had some old engines like this and the boilers were very good steamers, but it is not possible to get as many tubes into a given barrel diameter as with the zig-zag nesting.

On a Colonial railway, with very bad water and trouble with firebox tubeplates, we improved conditions very much in new plates by swaging down the tube ends and so increasing the bridge between tube holes from $\frac{5}{8}$ in. to $\frac{3}{4} \mathrm{in}$.

Mr. D. C. Fletcher (G.N.R., Manchester): With reference to water-space stays, the Author points out there is no standard with regard to diameters and areas supported, and that with pressures of I6olbs. it was usual to use in. diameter stays to support an area of 16 sq. inches, but with higher pressures the area is reduced, or larger-sized stays are used. The question I wish to ask is, why in steam motor boilers of the locomotive type with boiler pressures of 2oolbs. per sq. inch the makers find it only necessary to put

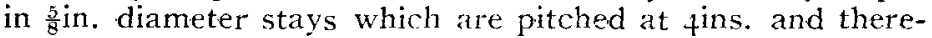
fore also supporting 16 sq. inches of surface The stays are steel and the inner firebox is entirely steel.

With regard to fireholes, I see no reference to firehole protector plates. The life of bottom half of the plate round the firehole is very much prolonged by the use of a steel plate about I 8ins. by 6ins. wide, bedded on to the copper plate and fastened with three rivets or bolts.

Under the heading of tubes the Author points out there is no settled practice as to whether ferrules should be fitted to new boilers. I believe on certain railways when tubes are renewed no ferrules are fitted until after an engine has completed a certain mileage, for it is a fact that after a general repair an engine, in a very little while, does often require a new set of ferrules to keep the tubes tight.

The Author refers to gun-metal seatings. On several boilers I have recently seen a drop forging is studded on to each back and front bottom corner of the firebox. It has two holes at right angles for washing out the side and front 
waterways. These holes are closed with ordinary brass taper plugs, and not screwed caps.

Steam domes of the type the Author shows must be very convenient when repairs have to be done to the regulator. A dome joint which frequently gives trouble through leaking is sometimes due to the top angle ring being weak, and consequently springing when the studs are tightened down; this is especially liable if copper joints of the narrow type are used.

The Chairman: In Fig. 8 we have an arrangement in which the designer has apparently attempted to prevent the upward expansion of the firebox by putting in a number of extra stays which are presumably intended to act as cantilevers. There is, however, a still more reprehensible practice of attempting the same thing by actually increasing the diameter of the upper two or three rows of stays and so introducing rigidity where flexibility is beyond anything desirable. The reasoning appears to be "these stays break, therefore put in more or thicken them "; why they break, whether on account of lateral bending or direct tension, does not appear to have been considered.

Whilst on the subject I might mention thith the early L. \& N.W. compounds had the first two or three vertical rows of stays behind the firebox tubeplate made of links, pins and eyebolts in each plate. This method was adopted because the water space was very narrow on account of the firebox being widened at the tubeplate. These stays did not break.

Mr. Jackson: There is the question regarding the advisability or otherwise of providing expansion stays at the tubeplate end of a direct stayed firebox. One would imagine that if the roof of the copper box is rigidly stayed to the roof of the steel shell, without allowance for the upward expansion of the tubeplate, trouble would ensue with either the tubeplate or the copper roof plate.

The Chairman: In Fig. 3 there is shown a vertical stay arrangement in which there is a large unsupported span of wrapper plate between the last side stay and the first crown stay; this part of the plate must necessarily be under a severe bending moment and must breathe considerably with pressure variations.

Mr. S. Clayton: The Author refers to the use of longitudinal stays between the tubeplates of boilers, and remarks on the diffculty of "washing-out" and "replacements" occasioned by the use of these stays. 
In my experience of the use of these longitudinal stays I have found they give very little trouble, they rarely break, and a leakage at either end is the exception; and they certainly serve the purpose for which they are installed, without providing a further source of leakage and fracture, such as tubeplates stayed with screws or beaded tubes are liable to.

Mr. Fletcher: On some makes of steam motor boilers in which there are 50 tulses, size $1 \frac{1}{4}$ ins. diameter by $3 \mathrm{ft}$. 2 ins., six of these tubes are screwed at both ends, and after they are placed in the boiler they are expanded and beaded into both tubeplates. These tubes then act as longitudinal stay tubes. If these stay tubes are renewed with plain tubes expanded in the ordinary way, no ill-effects are noticed. It would therefore appear stay tubes are no advantage.

Mr. Jackson: Speaking in general terms, one would certainly say that tubeplate stays in the tube area are not worth putting in.

Longitudinal stays between tubeplates instead of palm stays to the copper plate seem to be in vogue at present, but whether they are advantageous or not I cannot say.

The Author: Regarding the practice of employing a number of stays, either of the plain or tube pattern, between the front and back tubeplate, I should like to hear an expression of opinion from someone having actual experience.

Mr. T. Greaves (Visitor; G.C. Rly.) : I should like to know if the designers ever consider the running shed staff when they place the wash-out plug holes in some of the positions we find them in.

My reason for asking the question is this; we get instructions that when washing-out we should remove all the wash-out plugs. In that case we should have to first remove a good many of the fittings as well.

Mr. E. W. Selby (L. \& N.W. Rly., Horwich) : One of the points mentioned in the discussion was the practice (in vogue on the G.W.R.) of omitting the special flexible stays and carrying the ordinary vertical crown stays right to the front of the firebox. These stays are more flexible in practice owing to the distance between the inner and outer firebox crowns being greater on these engines than is usual in this country.

The G.W.R. and S.E. \& C.R. use $\frac{5}{8}$ in. diameter special steel stays with their copper fireboxes. These stays are not riveted but are caulked with a special tool both inside 
the box and out, and then nutted with ordinary steel nuts on the inside only.

If a nut begins to burn away, it is easily renewed and the thread thus preserved. When the boiler has a general repair, $\frac{3}{4}$ in. steel stays are used to replace the $\frac{5}{8}$ in. In this way considerable life is obtained from the firebox before there is any question of the stay holes damaging the copper plate or of the stays becoming too stiff on account of their large diameter. The pitch is about 3 ins. for a boiler working at $225 \mathrm{lbs}$. per sq. inch. I understand that these boilers are extremely satisfactory in service and run very long mileages between repairs, in spite of the exceptionally high pressure which they carry.

As regards the spacing of flue tubes round the sides and top corners of the firebox copper tubeplate, it is certainly an advantage to increase the width of the "bridges" in this region. For tubes $1 \frac{3}{4}$ ins. to 2 ins. diameter the bridges should nowhere be less than $\frac{3}{4}$ in., whilst for the outside rows a bridge of $\mathrm{I}$ in. has been found very beneficial on the L. \& Y.R. The large superheater flue tubes are also kept well away from the top corners on L. \& N.W.R. engines of both divisions.

Mr. Glover: In my experience go per cent. of boiler troubles are caused by the use of bad water, and it would be interesting to hear if any good results have been obtained from top feed fittings.

Mr. Gresham: I have had no actual experience with top feed, but some little time ago we made an injector for one of the railway companies in which arrangements were made to introduce live steam into the feed water as it emerged from the delivery cone, and by this means water was fed into the boiler at about 34 odeg.F. But I understand that, although this device was intended as a panacea to boiler scaling evils, it did not, in practice, do all that was expected of it.

The Author: About 25 years ago Sir John Aspinall, when Chief Mechanical Engineer of the Lancashire and Yorkshire Railway, tried the effect of turning the injector delivery pipes upwards into the steam space and against small deflectors, but unfortunately I am not able to say if material advantage accrued; but it would hardly appear so, as the practice was not perpetuated; still, the matter is of interest as a preliminary stage in top feeding. 